EGU2020-1394

https://doi.org/10.5194/egusphere-egu2020-1394

EGU General Assembly 2020

(c) Author(s) 2021. This work is distributed under

the Creative Commons Attribution 4.0 License.

\title{
Cr6+ adsorption by modified vermiculite
}

\author{
Valeria Medoro ${ }^{1}$, Celia Marcos Pascual ${ }^{2}$, Giacomo Ferretti ${ }^{1}$, Giulio Galamini ${ }^{1}$, and Massimo \\ Coltorti $^{1}$ \\ ${ }^{1}$ University of Ferrara, Department of Physics and Earth Sciences, Ferrara, Italy (valeria.medoro@unife.it) \\ 2University of Oviedo. Department of Geology, Oviedo, Spain (cmarcos@uniovi.es)
}

\section{Abstract: $\mathrm{Cr}^{6+}$ adsorption by modified vermiculite}

Valeria Medoro- University of Ferrara, Department of Physics and Earth Sciences, Italy

Celia Marcos Pascual-University of Oviedo, Department of Geology, Spain

Giacomo Ferretti- University of Ferrara, Department of Physics and Earth Sciences, Italy

Giulio Galamini- University of Ferrara, Department of Physics and Earth Sciences, Italy

Massimo Coltorti- University of Ferrara, Department of Physics and Earth Sciences, Italy

This work aimed at investigating the adsorption of $\mathrm{Cr}^{6+}$ in water by exfoliated vermiculite. The adsorbant tested in this experiment was a vermiculite (from China) which has been subjected to heating at $1000^{\circ} \mathrm{C}$ for 1 minute, resulting in an exfoliated vermiculite.

Three effects were studied: 1) contact time; 2) initial concentracion of $\mathrm{Cr}^{6+}$; 3) adsorbent mass. Samples were analysed by X Ray Fluorescence (XRF), X Ray Diffraction (XRD) and the solutions with Inductively Coupled Plasma Mass Spectrometry (ICP-MS) to quantify the adsorbed $\mathrm{Cr}^{6+}$ by the vermiculite.

Results from XRD diffraction showed a conversion of vermiculite into flogopite after heating at $1000^{\circ} \mathrm{C}$ for 1 minute because of: 1) high content of potassium, 2) dehydration and 3) structural reordering; after the contact of vermiculite with $\mathrm{Cr}^{6+}$, the mineral structure did not change. The adsorption of $\mathrm{Cr}^{6+}$ was studied by Langmuir, Freundlich and Dubinin-Kaganer-Radushkevich (DKR) isotherm models. DKR model, indicative of a cooperative process, described adsorption equilibrium better than the other two models and the maximum adsorption capacity obtained was of $2.81 \mathrm{~mol} / \mathrm{g}$. Kinetic was studied using pseudo-first and pseudo-second order kinetic models, with a better description of the process by pseudo-second order model with correlation coefficient almost unitary $\left(R^{2}=0.9984\right.$; other kinetic parameters were $k_{2}=0.0015$ and the absorption initial rate 
of $0.2 \times 10^{-8} \mathrm{mg} \mathrm{g}^{-1} \mathrm{~h}^{-1}$ ).

The present study demonstrates the effectiveness of modified vermiculite adsorbents for the treatment of hexavalent chromium-contaminated waters and that its adsorption depends on the experimental conditions (such as contact time, initial concentracion of $\mathrm{Cr}^{6+}$ and adsorbent mass). 